\title{
Laparoscopic trans teres vault suspension, a new laparoscopic method of treatment of female genital prolapse - a preliminary report
}

\author{
Ewa Milnerowicz-Nabzdyk, Mariusz Zimmer \\ $2^{\text {nd }}$ Department and Clinic of Obstetrics and Gynaecology, Wroclaw Medical University, Wroclaw, Poland
}

\begin{abstract}
Introduction: Pelvic organ prolapse (POP) is treated with a great variety of procedures and none is fully satisfactory. The aim of the study was to introduce and evaluate the effectives of laparoscopic trans teres vault suspension (LTTVS) technique as a new method for POP treatment.

Material and methods: In the years 2013-2014, eight symptomatic women with grades II-IV POP underwent LTTVS procedure. The mean age of patients was 65.25 years (range from 52 to 76 years). The surgery encompassed total hysterectomy, suturing the vagina and fixation of uterosacral ligaments to the vaginal stump, fixation of stumps of round ligaments to the vaginal stump, and fixation of the vaginal stump to the anterior rectus fascia. Mean follow-up was 17.75 months (range from 6 to 27 months).

Results: Eight patients were successfully operated. The symptoms of POP resolved after surgery and subjective quality of life increased. In one case a complication such as common fibular nerve injury appeared; however, it resolved after one month of physiotherapy. The other patient reported radiating pain down the leg after three months. No recurrence of vaginal stump prolapse was observed during the follow-up.

Conclusions: LTTVS is a promising method for POP treatment. Due to repair with the use of native tissues, physiological placement of vaginal stump, and high efficacy it can be considered as an alternative to other POP surgeries. The method requires additional research on larger groups of patients.
\end{abstract}

Key words: pelvic organ prolapse, uterine prolapse, laparoscopic, hysterectomy, vaginal stump suspension, minimally invasive surgery.

\section{Introduction}

Genital prolapse is a common disorder in women at large. It can happen to women of any age; however, it occurs most frequently in the postmenopausal period. This condition can develop also in younger, active women, for whom it is a troublesome issue. A great variety of modalities used to treat this disorder indicate that there is still a lack of sufficiently good methods that could remove its symptoms completely [1-16].

Methods for treatment of uterine prolapse are constantly being searched for and developed, so different operative techniques were regarded as the treatment of choice for this disorder at different stages of medicine development. Among the first, there were vaginal or abdominal techniques of suspension of uterus, cervix, or vaginal stump to various anatomical structures with the use of the own tissues (sacrospinous, uterosacral, and round ligaments). In the case of vaginal surgeries, they were combined with vaginal repair, and in the case of patients who are no longer sexually active, the ultimate treatment was colpocleisis based on various modifications. Later, other supportive materi- als were used i.a. parts of fascia lata, fasciae grafted from cadavers, or artificial elements such as meshes or tapes. The structure and functionality of these artificial materials has been developed over the years in order to meet medical needs. Introduction of laparoscopy to everyday practice has had revolutionised abdominal techniques used up to this time. This minimally invasive and precise approach has enabled surgeons to see all areas and anatomical structures of the minor pelvis and to use different angles of vision.

Because of many reports describing erosions of mesh inserted by vaginal approach, again the preferred operative method became vaginal operation with the use of native tissues. Among abdominal operations, laparoscopic sacrocolpopexy remained a gold standard for a total repair of anterior, middle, and posterior defect. This advanced technique is highly effective; however, it is also burdened with certain deficiencies such as intrusion to the area of retroperitoneal nerve plexuses, non-physiological placement of the vagina, and fixation to the sacrum associated with a certain risk of vascular complications $[2,3,15,17]$. 
The aim of the study is to assess the efficacy of laparoscopic trans teres vault suspension (LTTVS) in the operative treatment of uterine prolapse. This is a preliminary report.

\section{Material and methods}

In the years 2013-2014, eight repair surgeries for female genital organ prolapse were performed. Enrolled women aged 52-76 years had suffered from at least grades II-III pelvic organ prolapse (POP). The procedure consisted of the vaginal stump suspension to the anterior rectus fascia along with round and uterosacral ligament fixation to the vaginal stump. Non-absorbable sutures were used. Additionally, in women with anterior defect, vaginal repair was performed simultaneously or as the first or second stage of the surgical procedure. Follow-up time was 6-27 months. All the patients gave informed consent prior to surgery.

All surgeries in the study were conducted by the same surgeon. The LTTVS procedure consists of the following steps:

1. Total laparoscopic hysterectomy.

2. Suturing the vagina and fixation of uterosacral ligaments to the vaginal stump.

3. Bilateral skin incision above the proximal end of the round ligament.

4. Bilateral dissection of the anterior rectus fascia or aponeurosis.

5. Capturing the sutured vaginal stump by a doublesided, twofold, non-absorbable thread.

6. Dragging the non-absorbable suture through the round ligaments with the use of tubing forceps.

7. Suturing stumps of round ligaments to the vaginal stump with non-absorbable suture.

8. After deflation of the abdomen, pulling the sutures and their fixation to the anterior rectus fascia or aponeurosis.

9. Skin suturing.

Cases of patients treated with the described procedure:

Patient no. 1, aged 52 years, was operated on 19.02.2013. The patient presented the following symptoms: sensation of pulling in the lower abdomen, lower abdominal pain, and no problems with urination. Indications for surgery included: hyperplasia sine atypia and II-III grade POP. Surgical intervention: laparoscopic hysterectomy with appendages; V-LOCK suspension of the round and uterosacral ligaments to the vaginal stump; the vaginal stump suturing through the round ligament to the anterior rectus fascia with 2.0 sutures Ethibond Excel ${ }^{\mathrm{TM}}$ (Ethicon Inc., Somerville, NJ, USA).

Patient no. 2, aged 57 years, was operated on 23.05.2013. The patient had suffered from uterus bulging for several years; however, POP was diagnosed a year earlier. The patient reported the feeling of incom- plete emptying of the bladder, the need to urinate more often, and pulling pain in the lower abdomen. Indication for surgery was IV grade POP. Surgical intervention: laparoscopically assisted vaginal hysterectomy $(\mathrm{LAVH})$ with appendages along with anterior repair; V-LOCK suspension of round and uterosacral ligaments to the vaginal stump; vaginal stump suturing through round ligament to anterior rectus fascia with 2.0 Ethibond sutures.

Patient no. 3, aged 76 years, was operated on 24.05.2013. The patient had suffered from uterus bulging for several years, and POP was diagnosed one and a half years earlier. The patient reported the need to urinate more often, urine retention in the bladder, and pulling pain in the lower abdomen. Surgery was performed due to total IV grade POP. Indication: total IV grade POP. Surgical intervention: LAVH with appendages along with anterior repair; V-LOCK suspension of the round and uterosacral ligaments to the vaginal stump; vaginal stump suturing through the round ligament to the anterior rectus fascia with 2.0 Ethibond sutures.

Patient no. 4, aged 60 years, was operated on 9.12.2013. The patient had suffered from uterus bulging for three years, and POP was diagnosed ten months earlier. The patient reported the need to urinate more often, urine retention in the bladder, and pulling pain in the lower abdomen. Indication for surgery included III grade POP; middle and anterior defect, and minor posterior defect. Surgical intervention: LAVH with appendages; suspension of the round and uterosacral ligaments to the vaginal stump with Vicryl 0 sutures (Vicryl $^{\top M}$, Ethicon Inc., Somerville, NJ, USA); vaginal stump suturing through the round ligament to the anterior rectus fascia with 2.0 Ethibond sutures.

Patient no. 5, aged 76 years, was operated on 29.10.2013. The patient had suffered from uterus bulging for five years, and POP was diagnosed a year and a half earlier. The patient reported the need to urinate more often, urine retention in the bladder, and pulling pain in the lower abdomen. Indication: total IV grade POP. Surgical intervention: first stage operation - anterior and posterior repair was on 5.07.2013; second stage treatment for III grade POP and middle defect mainly included LAVH with appendages; suspension of the round and uterosacral ligaments to the vaginal stump with Ethibond 2.0 sutures; vaginal stump suturing through the round ligament to the anterior rectus fascia with 2.0 Ethibond sutures.

Patient no. 6, aged 63 years was operated on 05.03.2014. The patient had suffered from uterus bulging for two years and POP was diagnosed half a year earlier. The patient reported the need to urinate more often, urine retention in the bladder, and pulling pain in the lower abdomen. Indication: III grade POP; middle and anterior defect, and minor posterior defect. Surgical intervention: LAVH with appendages; suspension 
of the round and uterosacral ligaments to the vaginal stump with Ethibond 2.0 sutures; vaginal stump suturing through the round ligament to the anterior rectus fascia with 2.0 Ethibond sutures.

Patient no. 7, aged 69 years, was operated on 13.06.2014. The patient had suffered from uterus bulging for three years, and POP was diagnosed eight months earlier. The patient reported the need to urinate more often, urine retention in the bladder, and pulling pain in the lower abdomen. Indication: total IV grade POP. Surgical intervention: LAVH with appendages; suspension of the round and uterosacral ligaments to the vaginal stump with Ethibond 0 sutures; vaginal stump suturing through the round ligament to the anterior rectus fascia with 2.0 Ethibond sutures. Complication common fibular nerve injury, which resolved after one month of physiotherapy.

Patient no. 8, aged 69 years, was operated on 19.11.2014. Indication: total III grade POP. The patient had suffered from uterus bulging for three years, and POP was diagnosed eight months earlier. The patient reported the need to urinate more often, urine retention in the bladder, and pulling pain in the lower abdomen. Surgical intervention: LAVH with appendages; suspension of the round and uterosacral ligaments to the vaginal stump with 0 Ethibond sutures; the vaginal stump suturing through the round ligament to the anterior rectus fascia with 0 Ethibond sutures. Complications: side effects of anaesthetics (nausea and vomiting). The patient has suffered from fatty liver for many years and remained under supervision of a liver clinic both before and after operation.

\section{Results}

In the study, eight symptomatic women were enrolled. The mean age of patients was 65.25 years (range from 52 to 76 years). The time of observation after surgery ranged from 6 to 27 months (mean 17.75 months).

All of the eight patients were operated successfully with the use of LTTVS. In each woman, a defect of pelvic organs placement was corrected. Symptoms of POP resolved and no recurrence of vaginal stump prolapse was observed during the follow-up period. The surgical repair was most effective in women with apical defect or with associated medium-grade anterior and posterior defect. In patients with large grade combined defect (apical, posterior, and anterior), the best treatment results were achieved when the procedure of laparoscopic vaginal stump suspension was combined with anterior and posterior vaginal repair performed preferably at one stage.

Subjective quality of life increased to $7-10$ points out of 10. All patients denied symptoms of POP. No complications appeared except in one patient with common fibular nerve injury, which resolved after one month of physiotherapy and another patient who reported radiating pain down the leg after three months. Detailed condition of pelvic organs before and after LTTVS and the level quality of life are summarised in Table I.

In the case of high-grade defect, both apical and anterior and posterior, the best treatment results were obtained when the procedure of laparoscopic vaginal stump suspension was combined with anterior and posterior vaginal repair, preferably performed at the same time.

\section{Discussion}

In the study, a new method of POP treatment with the use of LTTVS technique is described. Our method has many advantages. One is the possibility to use native tissues without the need to applying tapes, which are not always tolerated well. The other is the physiological placement of the vaginal stump, which is an advantage over methods using vaginal stump suspension to structures that are physiologically not attached to it, such as the sacrum. The application of non-absorbable sutures to strengthen physiological ligamentous support of the uterus seems to be much less aggravating than implantation of mesh, often resulting in greater response from adjacent tissues [11, 18]. Reinforced natural supportive material built from rectus abdominis muscles and round ligament - shortened and strengthened by non-absorbable sutures, can be considered as corrected native material. Some authors regard this modality as the preferred choice for POP repair [5, 7, 11]. Another advantage of the proposed method is the possibility of performing radical surgery, i.e. the removal of the entire uterus without the necessity of leaving the cervix. Many authors believe that supravaginal uterus amputation is associated with lower risk of complications such as mesh erosion than total hysterectomy; therefore, the first modality is recommended when mesh implantation is considered for surgical repair [2, 19]. Such recommendations do not apply when sutures are used for vaginal stump suspension. A large group of authors believe that a better technique for the correction of a prolapsed uterus is operation without removal of the cervix, maintaining the natural suspensory apparatus of a ring built from the ligaments attached to the cervix. Others argue, however, that due to the damage to this ligamentous apparatus, it is no longer able to perform its suspensory function. In randomised trials, after five-year follow-up, a lower rate of urinary incontinence was observed in patients with total hysterectomy than in those with subtotal surgeries. Eleven percent of women who had undergone subtotal abdominal hysterectomy experienced vaginal bleeding after operation. The rate of other complications did not differ between groups [3].

Currently, during the debate on the usefulness of morcellation, the additional argument questioning the 
Tab. I. Pelvic organs condition before and after laparoscopic trans teres vault suspension in eight patients

\begin{tabular}{|c|c|c|c|c|c|c|c|c|}
\hline \multirow[t]{2}{*}{ Patient } & \multirow{2}{*}{$\begin{array}{l}\text { Baseline } \\
\text { diagnosis }\end{array}$} & \multirow[t]{2}{*}{ Type of surgery } & \multirow{2}{*}{$\begin{array}{l}\text { After } \\
\text { surgery }\end{array}$} & \multicolumn{2}{|c|}{ After three months } & \multicolumn{2}{|c|}{ After one year } & \multirow[t]{2}{*}{ Last visit } \\
\hline & & & & Diagnosis & Quality of life & $\begin{array}{c}\text { After one } \\
\text { year }\end{array}$ & $\begin{array}{l}\text { Quality of } \\
\text { life }\end{array}$ & \\
\hline 1 & $\begin{array}{l}\text { 2-3 POP } \\
\text { II/III MD } \\
\text { I AD } \\
\text { I PD }\end{array}$ & $\begin{array}{c}\text { TLH + LTTVS } \\
\text { (stage I) }\end{array}$ & $\begin{array}{l}O M D \\
I A D \\
O P D\end{array}$ & $\begin{array}{l}O M D \\
I A D \\
O P D\end{array}$ & $\begin{array}{c}7 / 10 \\
\text { seldom } \\
\text { radiating pain } \\
\text { down the leg }\end{array}$ & $\begin{array}{l}O M D \\
I A D \\
O P D\end{array}$ & $8 / 10$ & $\begin{array}{c}11.05 .2015 \\
\text { O MD; I AD; O PD } \\
\text { QoL 9/10 }\end{array}$ \\
\hline 2 & $\begin{array}{l}\text { IV POP } \\
\text { IV MD } \\
\text { III AD } \\
\text { II PD }\end{array}$ & $\begin{array}{c}\text { LAVH + LTTVS } \\
+ \text { anterior and } \\
\text { posterior repair } \\
(\text { stage I) }\end{array}$ & $\begin{array}{l}0 \mathrm{MD} \\
O \mathrm{AD} \\
O \mathrm{PD}\end{array}$ & $\begin{array}{l}0 \mathrm{MD} \\
0 \mathrm{AD} \\
\text { I PD }\end{array}$ & $9 / 10$ & $\begin{array}{l}O M D \\
O A D \\
\text { I PD }\end{array}$ & $9 / 10$ & $\begin{array}{c}\text { 19.05.2015 } \\
\text { O MD; 0 AD; I PD } \\
\text { QoL 10/10 }\end{array}$ \\
\hline 3 & $\begin{array}{l}\text { IV POP } \\
\text { IV MD } \\
\text { III AD } \\
\text { II PD }\end{array}$ & $\begin{array}{c}\text { LAVH + LTTVS } \\
+ \text { anterior and } \\
\text { posterior repair } \\
\text { (stage I) }\end{array}$ & $\begin{array}{l}O M D \\
O A D \\
O P D\end{array}$ & $\begin{array}{l}O M D \\
\text { I AD } \\
\text { I PD }\end{array}$ & $8 / 10$ & $\begin{array}{l}0 M D \\
\text { I AD } \\
\text { I PD }\end{array}$ & $8 / 10$ & $\begin{array}{c}19.05 .2015 \\
\text { O MD; II AD; I PD } \\
\text { QoL 8/10 }\end{array}$ \\
\hline 4 & $\begin{array}{l}\text { III POP } \\
\text { III MD } \\
\text { II AD } \\
\text { I PD }\end{array}$ & $\begin{array}{c}\text { TLH + LTTVS } \\
\text { (stage I) }\end{array}$ & $\begin{array}{l}0 \mathrm{MD} \\
\mathrm{I} \mathrm{AD} \\
0 \mathrm{PD}\end{array}$ & $\begin{array}{l}O M D \\
I A D \\
O P D\end{array}$ & $8 / 10$ & $\begin{array}{l}O M D \\
I A D \\
O P D\end{array}$ & $8 / 10$ & $\begin{array}{l}11.05 .2015 \\
\text { O MD; I AD; O PD } \\
\text { QoL 10/10 }\end{array}$ \\
\hline 5 & $\begin{array}{l}\text { IV POP } \\
\text { IV MD } \\
\text { IV AD } \\
\text { III PD }\end{array}$ & $\begin{array}{l}\text { Anterior and } \\
\text { posterior repair } \\
\text { (stage I) } \\
\text { TLH + LTTVS } \\
\text { (stage II } \\
\text { after } 3 \mathrm{~m})\end{array}$ & $\begin{array}{l}O M D \\
\text { I AD } \\
\text { I PD }\end{array}$ & $\begin{array}{l}O M D \\
\text { I AD } \\
\text { I PD }\end{array}$ & $9 / 10$ & $\begin{array}{l}0 M D \\
\text { I AD } \\
\text { I PD }\end{array}$ & $9 / 10$ & $\begin{array}{c}13.05 .2015 \\
\text { O MD; I AD; II PD } \\
\text { QoL 9/10 }\end{array}$ \\
\hline 6 & $\begin{array}{l}\text { III POP } \\
\text { III MD } \\
\text { II AD } \\
\text { I PD }\end{array}$ & $\begin{array}{c}\text { TLH + LTTVS } \\
\text { (stage I) }\end{array}$ & $\begin{array}{l}O M D \\
\text { I AD } \\
\text { I PD }\end{array}$ & $\begin{array}{l}O M D \\
\text { I AD } \\
\text { I PD }\end{array}$ & $10 / 10$ & $\begin{array}{l}0 \mathrm{MD} \\
\text { I } \mathrm{AD} \\
\text { I PD } \\
\text { after } 9 \mathrm{~m}\end{array}$ & $10 / 10$ & $\begin{array}{c}11.05 .2015 \\
\text { O MD; I AD; I PD } \\
\text { QoL 9/10 }\end{array}$ \\
\hline 7 & $\begin{array}{l}\text { III POP } \\
\text { III MD } \\
\text { II AD } \\
\text { I PD }\end{array}$ & $\begin{array}{c}\text { TLH + LTTVS } \\
\text { (stage I) }\end{array}$ & $\begin{array}{l}0 \mathrm{MD} \\
\text { I AD } \\
\text { I PD }\end{array}$ & $\begin{array}{l}O M D \\
\text { I AD } \\
\text { I PD }\end{array}$ & $8 / 10$ & $\begin{array}{c}O M D \\
\text { I AD } \\
\text { I PD } \\
\text { after } 6 \mathrm{~m}\end{array}$ & $8 / 10$ & $\begin{array}{c}\text { 30.05.2015 } \\
\text { O MD; I AD; I PD } \\
\text { QoL 9/10 }\end{array}$ \\
\hline 8 & $\begin{array}{l}\text { III POP } \\
\text { III MD } \\
\text { II/III LD } \\
\text { I PD }\end{array}$ & $\begin{array}{c}\text { TLH + LTTVS } \\
\text { (stage I) }\end{array}$ & $\begin{array}{l}0 \mathrm{MD} \\
0 \mathrm{LD} \\
\text { I PD }\end{array}$ & - & $9 / 10$ & & & $\begin{array}{c}27.05 .2015 \\
\text { O MD; II LD; I PD } \\
\text { QoL 9/10 }\end{array}$ \\
\hline
\end{tabular}

AD - anterior defect; LAVH - laparoscopically assisted vaginal hysterectomy; LD - lateral defect; LTTVS - laparoscopic trans teres vault suspension; MD - middle defect; PD - posterior defect; POP - pelvic organ prolapse; TLH - total laparoscopic hysterectomy; QoL - quality of life

superiority of supravaginal uterus amputation over total hysterectomy appears. In older women who suffer from POP more frequently than younger patients, morcellation is associated with increased risk of complications [20]. Another question about the superiority of a laparoscopic procedure over open surgery can be asked. It is known that minimally invasive endoscopic procedure offers a lot of benefits to a patient. Moreover, preserving part of the uterus - the cervix with already stretched suspensory apparatus, which lacks its functionality - is of questionable value. A subtotal hysterectomy is also possible in the presented technique, which is an advantage for supporters of less radical uterine amputations; however, the authors are not convinced about the superiority of subtotal hysterectomy over total hysterectomy in the context of POP repair success. Five-year observation proves more benefits in relation to urinary incontinence and a lack of any advantage of supravaginal uterus amputation over total hysterectomy in terms of recurrence rate and other complications [3, 15]. Another doubt is whether removal of the uterus is reasonable for POP repair [4, 5, 8, 10, 14]. Citing a group of experts, "hysterectomy is not a method of POP treatment". However, the same experts believe that a golden method for a total repair of the three defects (anterior, middle, and posterior) is a procedure of sacrocolpopexy, in which total or subtotal hysterectomy is one of the stages [2, $3,15,17,21]$. Undoubtedly, this procedure has some limitations such as access into pararectal and perisacral space, which increases the risk of injury of the superior and inferior hypogastric plexuses and nerves, the obturator nerve, as well as the iliac, sacral, and rectal vessels. This technique is reserved for advanced operators who have excellent orientation in anatomical structures of the lesser pelvis with particular focus on rectovaginal and retroperitoneal pelvic floor space. Laparoscopies performed by such experienced surgeons are not without the risk of the mentioned complications. 
Hysterectomy is reasonable in POP repair in cases with highly stretched vagina. In such patients, uterine removal along with part of the vagina significantly shortens the non-functional organ and enables the surgeon to suspend it effectively. An unquestionable advantage of radical procedure is a priori prevention of further surgical intervention due to aging, and gradual tissue weakening leading to recurrence. Repeated operations are usually more difficult because every surgery changes the natural anatomical structures. If re-operation is required after uterus-preserving POP repair, removal of the remaining parts of genital organs may be necessary. Every following corrective surgery deletes the benefits from the previous operation and forces the operator to search for a new anatomical structure that can serve as a support for suspension. Considering all the pros and cons as well as the multiplicity of methods with or without uterine removal, the authors conclude that an excellent method does not exist, and each of them has its own disadvantages.

Our two-year experience shows that our procedure has the highest effectiveness in women with apical defect or with associated medium-grade anterior and posterior. In the case of high-grade defect both apical and anterior and posterior, the best treatment results were obtained when the procedure of laparoscopic vaginal stump suspension was combined with anterior and posterior vaginal repair, preferably performed at the same time. Similar observations can be found in the literature, where other authors suggest global POP repair performed in a single stage [10, 15, 16, 21]. Many operators are interested in a return to suspensions to anterior compartments of abdominal the cavity, among which anterior rectus fascia is the most popular. This allows us to believe that our technique may be effective also in long-term observations. Liang et al. proposed a suspension technique in which the whole uterus was suspended to the anterior abdominal wall fascia with the use of an inelastic non-absorbable mesh [4]. Kurt et al. performed minimally invasive, uterus-preserving ligamentopexy of the round ligament to the anterior rectus fascia with the use of a suprapubic and extraperitoneal approach. The procedure is simple; however, it is addressed mainly to younger women who wish to preserve their uterus after and before natural deliveries, or for older women for whom total hysterectomy would be too burdensome [10]. Both techniques required the use of additional anterior or posterior vaginal wall repair in cases of co-existing anterior or posterior defect. Dubuisson et al. from Switzerland described another modality. After supravaginal uterus amputation a mesh is attached to the puborectalis ligament (similarly as in sacrocolpopexy) but fixed to anterior vaginal wall with the use of tackers, and then the mesh arms are sutured on the both sides to the abdominal oblique fascia in the retroperitoneal space [22]. The limitation of the first method is the impossibility of its use in women with additional indication to removal of the uterus. The limitation of the second one is the mesh itself. On the one hand the mesh gives strong adhesion and good support, but on the other hand the placement of a vaginal foreign body may result in hypersensitivity reactions. Implantation of mesh is more effective in women with cervix-sparing procedure which reduces the risk of mesh erosion. Comparing our procedure to various modifications of uterus suspension to rectus anterior fascia with the use of abdominal approach [4, $10,14]$, especially to the technique developed by Kurt, which had no recurrence after five-year follow-up [10], the authors hope to obtain similarly high effectiveness in long-term observations. However, final conclusion requires a wider study group and extension to at least five-years follow-up. This is a preliminary report.

The limitations of the present report are the small study group and a lack of long-term follow-up; however, many authors describe new modalities of suspensions 6-26 months after operation [1, 2, 4]. In this preliminary report, we describe eight patients, but the study group is constantly growing, which allows us to collect new data and gather further experience. Another two patients aged 59 and 61 years old with grades III-IV POP underwent the LTTVS procedure while preparing this report, and the results will be presented in a full report of this study. In the present study, two-year follow-up showed high efficacy in middle defect repair and also high efficacy in middle defect combined with anterior and/or posterior defect. The evaluation of quality of life after operation increased to 7/10 - 10/10 and was much better than before the operation, according to subjective patient assessment. The efficacy of the method was evaluated objectively based on a five-point scale, where 0 denotes the lack of defect, I-III denotes the degree of the each defect, and IV denotes maximal descent of the uterus. Regarding group size, the authors modified the technique (vaginal stump suspension to round ligaments) regarded as ineffective and wanted to examine its efficacy first on small group of patients. During twoyear follow-up no recurrence of vaginal stump prolapse was observed. This enables the authors to believe that outcomes are promising; however, the assessment of the new technique requires a larger study group and longer follow-up.

\section{Conclusions}

LTTVS is a promising method for POP treatment. Among its advantages are repair with the use of native tissues, physiological placement of the vaginal stump, and high efficacy without any recurrence. LTTVS can be considered as an alternative to other POP surgeries. The method requires additional research on a larger group of patients and longer follow-up. 


\section{Disclosure}

This research was realized from grant St-640. Authors report no conflict of interest.

\section{References}

1. Khandwala S, Williams C, Reeves W, et al. Role of vaginal mesh hysteropexy for the management of advanced uterovaginal prolapse. J Reprod Med 2014; 59: 371-378.

2. Gracia M, Perello M, Bataller E, et al. Comparison between laparoscopic sacral hysteropexy and subtotal hysterectomy plus cervicopexy in pelvic organ prolapse: A pilot study. Neurourol Urodyn 2015; 34: 654-658.

3. Andersen LL, Zobbe V, Ottesen B, et al. Five-year follow up of a randomised controlled trial comparing subtotal with total abdominal hysterectomy. BJOG 2015; 122: 851-857.

4. Liang $H$, Chen $G$, Yu H, et al. Sling suspension: a new technique of treating uterine prolapse. Zhonghua Yi Xue Za Zhi 2014; 94: 1664-1666.

5. Iliev VN, Andonova IT. Uterus preserving vaginal surgery versus vaginal hysterectomy for correction of female pelvic organ prolapse. Prilozi 2014; 35: 243-247.

6. Alshaikh GK. Comparison of sacrospinous hysteropexy and uterosacral suspension for treatment of uterine prolapse. 123 Suppl 2014: 1102S.

7. Shrestha B, Marhatha R, Kayastha S, et al. Short-term versus long-term catheterization after vaginal prolapse surgery. Nepal Med Coll J 2013; 15: 102-105.

8. Alkis I, Karaman E, Han A, et al. The outcome of Manchester-Fotergill operation for uterine decensus repair: a single center experience. Arch Gynecol Obstet 2014; 290: 309-314.

9. Nicolau-Toulouse V, Tiwari P, Lee T, et al. Does bilateral sacrospinous fixation with synthetic mesh recreate nulliparous pelvic anatomy? An MRI evaluation. Female Pelvic Med Reconstr Surg 2014; 20: 222-227.

10. Kurt S, Canda MT, Tasyurt A. A new surgical method of suprapubic and extraperitoneal approach with uterine preservation for pelvic organ prolapse: kurt extraperitoneal ligamentopexy. ISRN Obstet Gynecol 2013; 2013: 748232.

11. Sekiguchi Y, Kinjo M, Maeda Y, et al. Reinforcement of suspensory ligaments under local anesthesia cures pelvic organ prolapse: 12-month results. Int Urogynecol J 2014; 25: 783-789.

12. Lin L, Wang P, Wang $Q$, et al. Laparoscopic modified sacral hysteropexy: initial experience with an original surgical approach to uterovaginal prolapse. J Minim Invasive Gynecol 2014; 21: 431-435.

13. Li M, Feng Y, Jin S, et al. Laparoscopic Y-shaped polypropylene mesh for uterine and vaginal vault prolapse. Zhongguo Xiu Fu Chong Jian Wai Ke Za Zhi 2013; 27: 1106-1109.

14. Rahmanou P, Price N, Jackson S. Laparoscopic hysteropexy: a novel technique for uterine preservation surgery. Int Urogynecol J 2014; 25 : 139-140.

15. Barber MD, Maher C. Apical prolapse. Int Urogynecol J 2013; 24: 1815-1833.

16. Eilber KS, Alperin M, Khan A, et al. Outcomes of vaginal prolapse surgery among female Medicare beneficiaries: the role of apical support. Obstet Gynecol 2013; 122: 981-987.

17. Parkes IL, Shveiky D. Sacrocolpopexy for treatment of vaginal apical prolapse: evidence-based surgery. J Minim Invasive Gynecol 2014; 21: 546-557.

18. Nazik H, Narin MA, Narin R, et al. Investigating the clinical significance of mesh peritonization in abdominal vault suspension surgery using a comparative rabbit model. Eur J Obstet Gynecol Reprod Biol 2014; 175: 199-204.

19. Gutman R, Maher C. Uterine-preserving POP surgery. Int Urogynecol J 2013; 24: 1803-1813.

20. Hill AJ, Carroll AW, Matthews CA. Unanticipated uterine pathologic finding after morcellation during robotic-assisted supracervical hysterectomy and cervicosacropexy for uterine prolapse. Female Pelvic Med Reconstr Surg 2014; 20: 113-115.

21. Gabriel B, Nassif J, Barata S, et al. Twenty years of laparoscopic sacrocolpopexy: where are we now? Int Urogynecol J 2011; 22: 1165-1169.

22. Dubuisson JB, Yaron M, Wenger JM, et al. Treatment of genital prolapse by laparoscopic lateral suspension using mesh: a series of 73 patients. J Minim Invasive Gynecol 2008; 15: 49-55. 